\title{
Research on Influence of Innovative Wind-Resistant Energy Dissipation Devices on Wind Pressures of Low-Rise Gable Roof Buildings Based on Wind Tunnel Test
}

\author{
Kai HE, Linsheng HUO, Gang LI \\ Faculty of Infrastructure Engineering \\ Dalian University of Technology \\ Dalian, China \\ e-mail: dluthk@foxmail.com, 1shuo@dlut.edu.cn,gli@dlut.edu.cn
}

\begin{abstract}
In the view of the serious problem of low-rise gable roof buildings damaged by typhoon, a method of using windresistant energy dissipation devices on roof wind pressure to reduce the damage of strong wind on low-rise gable roof buildings is proposed in this paper. The wind tunnel experiments were carried out to study the influence of windresistant energy dissipation devices on the roof wind pressure. The experimental results shown that the wind-resistant energy dissipation devices can reduce the worst negative pressure over the whole roof greatly. The mean negative wind pressure coefficients over the easily damaged area on windward roofs, such as the area near the ridge, contact edge of roof and gable, can be decreased 50 percent; When the upper part of the eaves is fitted with the wind-resistant devices and deflector, the extreme value of the mean wind pressure coefficient of the measuring points is significantly reduced at any wind direction, and the reduction amplitude is up to $40 \%$. The wind resistant effect is better than installing the wind-resistant energy dissipation devices alone or installing the deflector separately.
\end{abstract}

Keywords-low rise buildings; energy dissipation devices; wind tunnel tests; mean wind pressur

\section{INTRODUCTION}

The damage to the low-rise gable roof buildings is usually starts from the local damage of the roof, which can cause the destruction of other structural parts of the house [1]. Therefore, taking measures to reduce wind load of low-rise housing structure, especially the wind load of roof system [2], is crucial for improving the anti-wind ability of low-rise gable roof buildings.

In recent years, scholars at home and abroad have paid more attention to the wind pressure and wind resistance measures of gable roofs. Pindado S [3], Dai Y[4] et al. Studied the wind pressure on the roof of several adjacent low-rise buildings, and put forward the reasonable arrangement of houses. Huang peng et al. [5-7] conducted indepth study of roofing details, including the ridge and the gutter, etc. The results show that the wind pressure of roof can be reduced by the above detailed construction measures, and the wind resistance of roof can be improved; The scholar Xie Zhuangning [8], Chen yannan et al. [9] analyzed the flow characteristics of the air flow around the roof, and analyzed and confirmed that the vertical air deflector could reduce the roof pressure significantly.

In the field of civil engineering, the traditional anti-wind method of structure is to resist the damage of wind load by strengthening the bearing capacity and the integrity of the structure itself. For the low-rise gable roof buildings, the effect of traditional structure anti-wind measures is relatively unobvious, the cost is large, so the cost performance is not high. In recent years, structural damping control technology has been widely used in civil engineering seismic structures, such as high-rise structures and long-span structures. However, few researches have been done on the low-rise buildings, especially the anti-wind in the rural buildings. With the attention to the problems of low-rise rural buildings, as well as the gradual maturity of damping technology, the cost is gradually reduced, and it is feasible to apply dampers to the anti-wind field of low-rise rural buildings

According to the research status and existing problems of anti-wind measures of roof at home and abroad, the paper puts forward the method of installing wind-resistant energy dissipation devices on roof to improve the wind-resistance performance of roof, and gives a reasonable layout scheme.

\section{WIND TUNNEL TEST}

To prove the effect of the wind-resistant energy dissipation devices on reducing the negative pressure of the roof, and how to install the devices can make it play a better role. Therefore, the wind tunnel test is designed to comprehensively analyze the roof wind pressure of each wind direction angle.

\section{A. Test Equipment}

This experiment was completed with the wind tunnel test room of China Academy of building research. The wind tunnel adopts advanced AC variable frequency speed regulation system, the test section turntable and the moving test rack are controlled by microcomputer, and the degree of automation is higher

The B type surface roughness wind field, wind profile and turbulence intensity profile are simulated to meet the simulation requirements of atmospheric boundary layer [10].

\section{B. Test Model}

The low-rise house model plane size is $500 \mathrm{~mm} * 400 \mathrm{~mm}$, the cornice height is $450 \mathrm{~mm}$, and the blockage ratio meets the requirements of wind tunnel test. The damping device fan blade diameter is $40 \mathrm{~mm}$, and 5 sides are installed on the test side. 


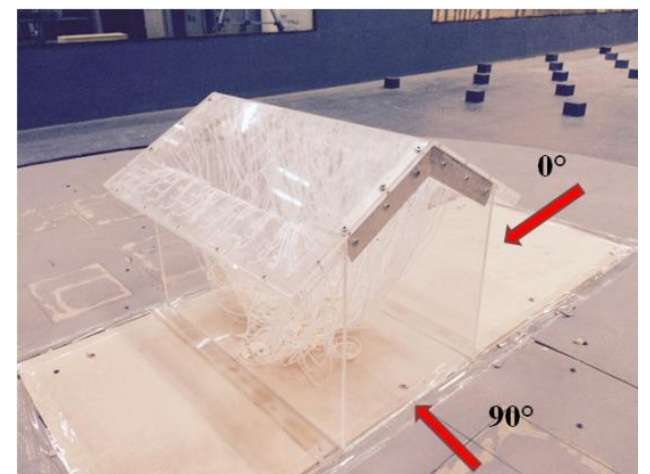

Figure 1. Model of rigid body pressure measurement and direction of wind direction.

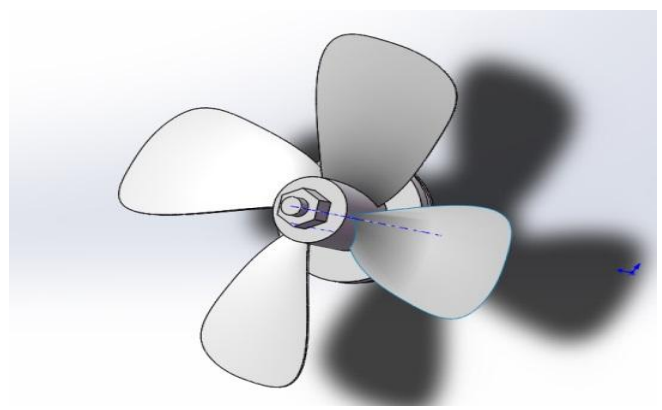

Figure 2. Schematic diagram of rotating blade of damping device.

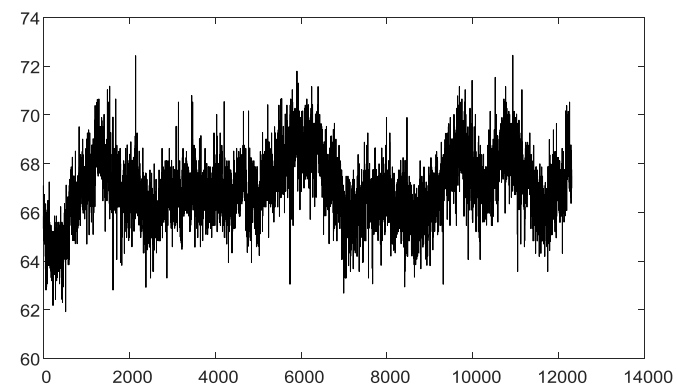

Figure 3. The date of one measurement point in a sampling time.

\section{Test Design}

The model is placed in the center of the rotary table, simulate the different wind angles by rotating the rotary table. The wind direction angle interval is 15 degrees clockwise to increase $\left(0^{\circ} \sim 360^{\circ}\right)$, a total of 25 wind direction Angle $\left(0^{\circ}\right.$ and $360^{\circ}$, the same as a review).Scanning valve scanning frequency is set to $400 \mathrm{~Hz}$, a the sampling time is $30.5 \mathrm{~s}$, can get 12300 data measurement points.

Six different test conditions are designed for the wind tunnel test, as follows
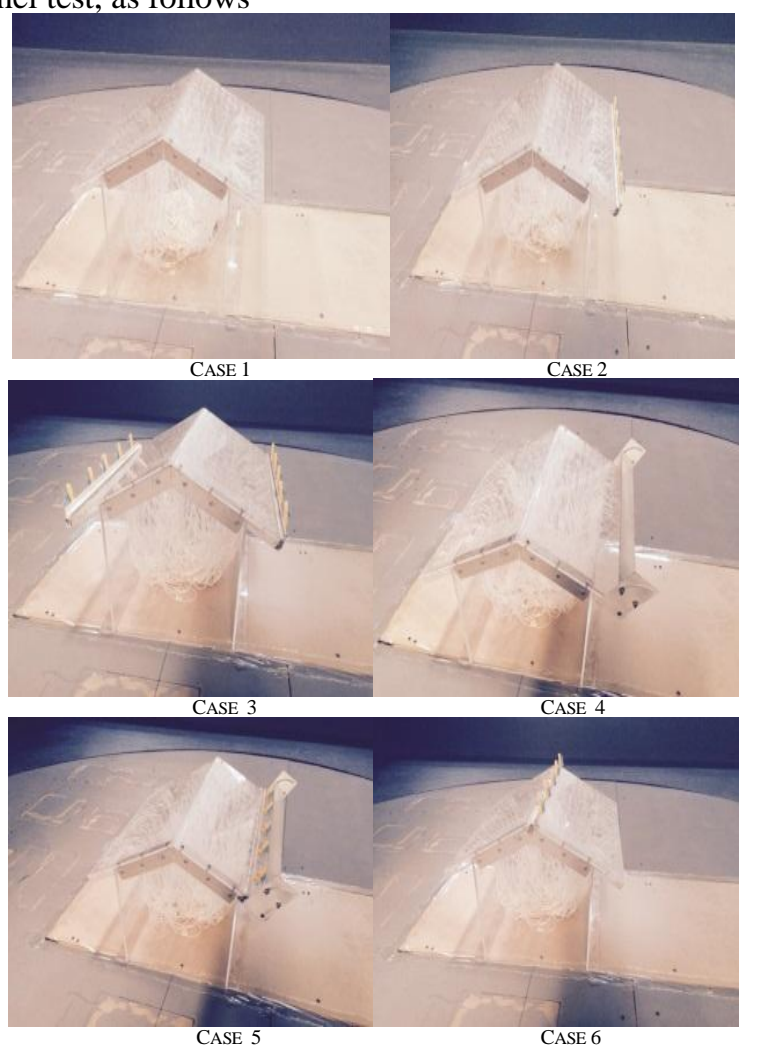

Figure 4. Model installation diagram under different working conditions.

TABLE I. TEST CONDITIONS

\begin{tabular}{|c|c|c|}
\hline Number & Case & $\begin{array}{l}\text { Angle of wind } \\
\text { direction }\end{array}$ \\
\hline 1 & No handling of roof (no control) & $0^{\circ} \sim 360^{\circ}, 15^{\circ}$ interval \\
\hline 2 & $\begin{array}{l}\text { Installing wind-resistant device at } \\
\text { single eave }\end{array}$ & $0^{\circ} \sim 360^{\circ}, 15^{\circ}$ interval \\
\hline 3 & $\begin{array}{c}\text { Installing wind-resistant device at } \\
\text { both eaves }\end{array}$ & $0^{\circ} \sim 360^{\circ}, 15^{\circ}$ interval \\
\hline 4 & Installing deflector at eaves & $0^{\circ} \sim 360^{\circ}, 15^{\circ}$ interval \\
\hline 5 & $\begin{array}{l}\text { Install wind-resistant device and } \\
\text { deflector above eaves }\end{array}$ & $0^{\circ} \sim 360^{\circ}, 15^{\circ}$ interval \\
\hline 6 & $\begin{array}{l}\text { Installing wind-resistant device at } \\
\text { ridge }\end{array}$ & $0^{\circ} \sim 360^{\circ}, 15^{\circ}$ interval \\
\hline
\end{tabular}




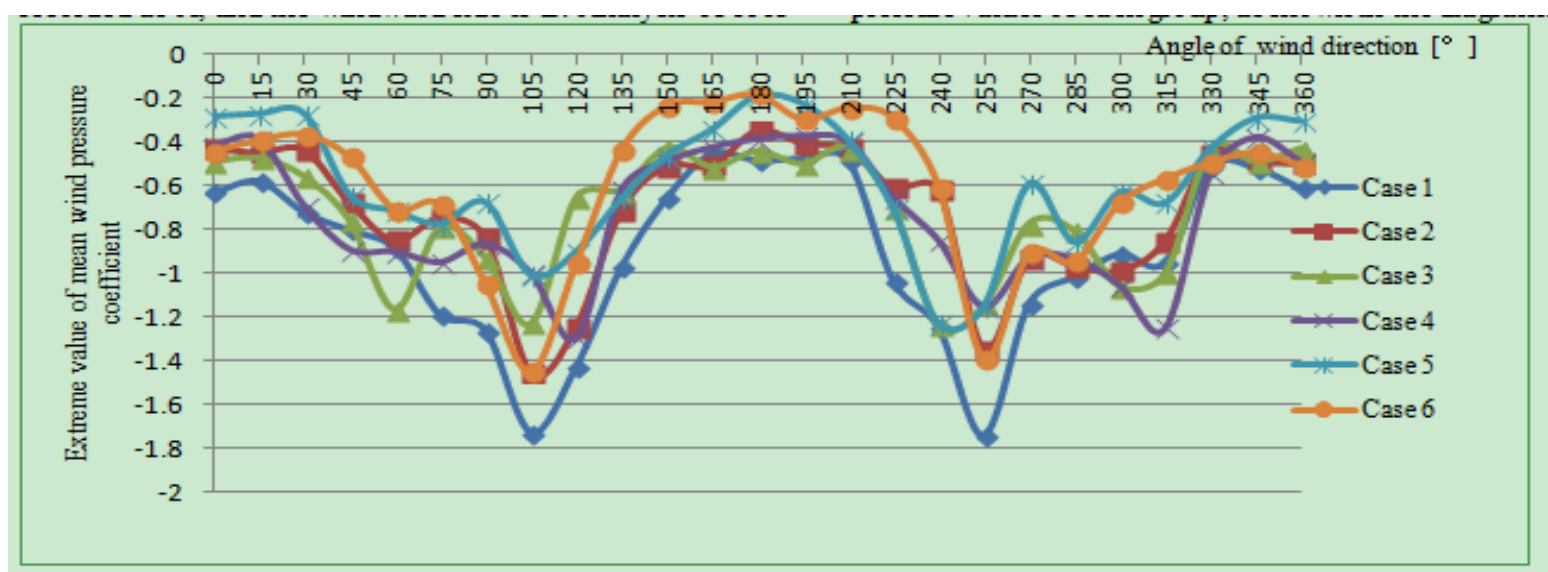

Figure 5. Extreme negative pressure extreme value curve of roof A (leeward roof).

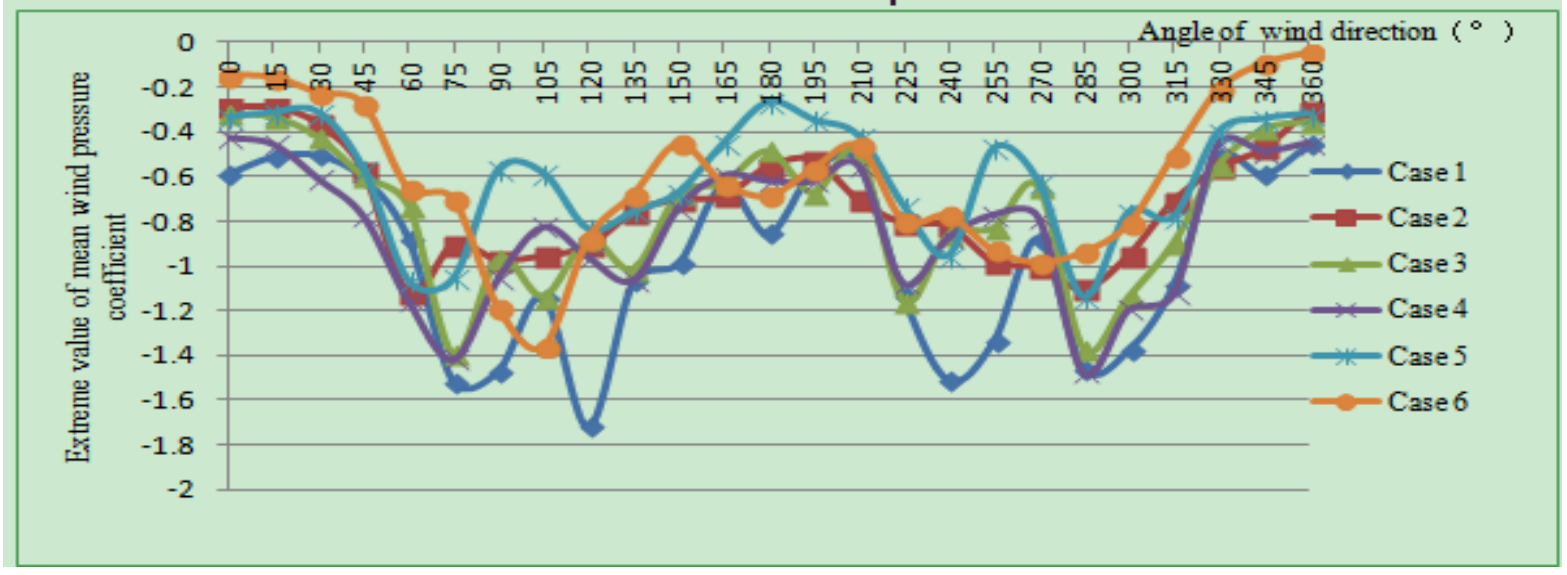

Figure 6. Extreme negative pressure extreme value curve of roof B (Windward roof).

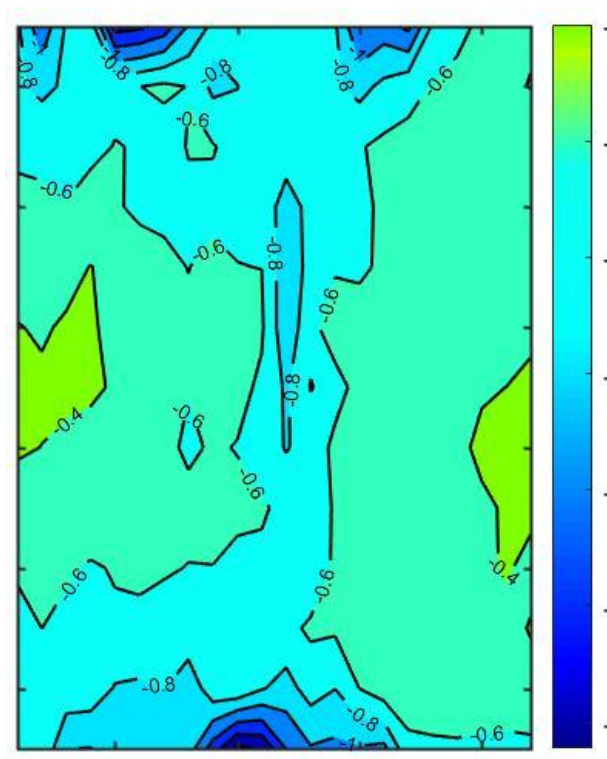

No control roof

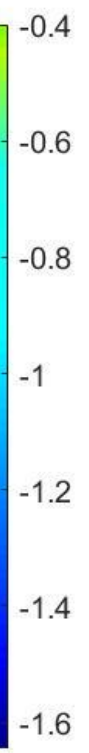

$-1.6$

Figure 7. The nephogram of the most unfavorable wind pressure coefficient of each measuring point

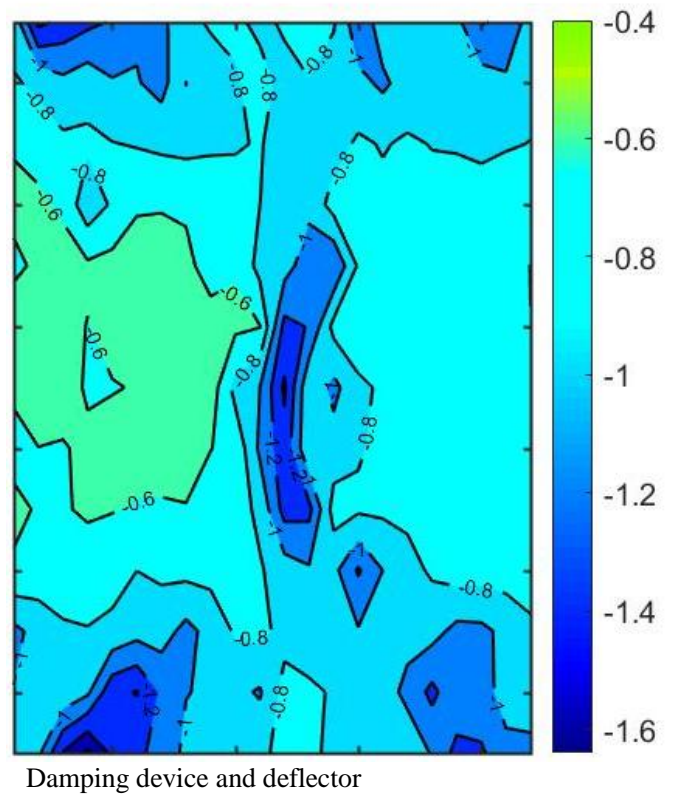

Damping device and deflector
$-0.4$

$-0.6$

.8

1.2

$-1.4$

1.6 


\section{TEST RESULTS AND ANALYSIS}

B In order to explore the ability of the wind resistant device to improve the roof wind pressure. This test is from a variety of wind angles, objectively and comprehensively judged the effect of wind-resistant device on the roof wind pressure. At the $0^{\circ}$ wind direction, the leeward side of the gable house is recorded as A, and the windward side is B. Analysis of roof wind condition by extreme value of negative pressure.

According to the average wind pressure coefficient of each measuring point, the most unfavorable negative pressure value of each wind direction under each case is selected. Draw the curves of the most unfavorable wind pressure values of each group, as shown in the diagram:

Observing the curves of figure 5 , by comparing the trend of the most unfavorable negative pressure extreme curve in each case, it is found that the absolute value of the most unfavorable wind pressure coefficient is smaller when the wind direction is close to the vertical ridge direction $\left(0^{\circ}, 180^{\circ}\right)$. When the wind angle is about $105^{\circ}$ and $255^{\circ}$, the maximum negative pressure appears in the roof, which accords with this rule under each Case. When the typical gable roof is not controlled (Case 1), the extreme value of the point average wind pressure coefficient is more than -1.6, which is very unfavorable. After taking different wind resistant measures to the roof (Case 2 5), it can be seen from the curve that the maximum negative pressure value has been improved to varying degrees. Among them, the better effect is the Case 4 and the Case 5, and the most unfavorable negative pressure drop is about -1.2 .

Observing the curves of figure 6 , by comparing the trend of the most unfavorable negative pressure extreme curve in each case, it is found that the most unfavorable negative pressure still appears at $105^{\circ}$ and $255^{\circ}$ of wind direction. This shows that for the gable roof house, under the influence of wind suction, $105^{\circ}\left( \pm 10^{\circ}\right)$ and $255^{\circ}\left( \pm 10^{\circ}\right)$ are the most unfavorable wind direction angle. And in these wind direction, wind damping effect is more obvious (from -1.7 to -1.0).For the B roof, after the roof adopts different wind resistance measures (case 2 5), the roof wind pressure improvement effect is also very obvious. Among them, the better effect is the case 2 and the case 5

Observing the figure 7 , the comparison of the wind pressure coefficient of the roof of two cases is very clear. From the nephogram, the extreme negative pressure extreme value of each measuring point is reduced. The extreme value and the value is reduced to about -0.8 after installing the wind-resistant device of negative pressure at ridge and the value of contact edge between the roof and the gable is very large $(-1.5$ or more).

\section{CONCLUSION}

The existence of a new type of rotary wind resistant energy dissipation device has obvious effect on reducing the most unfavorable negative pressure of the roof, and the failure area of the windward roof often occurs, such as the ridge, the contact edge between the roof and the gable, the average negative wind pressure coefficient can be reduced by $50 \%$;

According to the analysis of the experimental data, when the low double slope roof house is affected by the wind, the negative pressure extreme value of the leeward side is generally greater than the windward side. Therefore, if the roof is damaged by wind suction, the damage occurs first on the leeward roof or local damage (near the ridge, roof edge).Based on the analysis of the extreme negative pressure extremum, the concept of the most unfavorable wind direction angle is put forward: The wind direction that is perpendicular to the roof is defined as $0^{\circ}$, wind whirled counterclockwise, the most unfavorable negative pressure extremum appeared in the $105^{\circ}\left( \pm 10^{\circ}\right)$ and $255^{\circ}\left( \pm 10^{\circ}\right)$ range. This has guiding significance for local reinforcement of housing roof, optimal selection of building orientation and reasonable placement of wind-resistant device.

Through the wind tunnel test data of multi condition analysis, an optimal installation method of wind-resistant device is proposed: Install wind-resistant device and deflector above eaves (case 5), to significantly reduce the suction of the harmful effects of roof structure. Under the condition of any wind direction, the extreme value of the mean wind pressure coefficient (including the front and the leeward) are significantly reduced, and the reduction rate can reach $40 \%$. The reduction is higher than the installation of wind-resistant device alone, the installation of deflector and the installation of wind-resistant device at the ridge.

\section{ACKNOWLEDGMENT}

This works is supported by the National "12th Five-year" Plan for Science \& Technology Pillar Program (2014BAL05B03). Innovation Group Program of National Natural Sciences Foundation of China (51421064).

\section{REFERENCES}

[1] Yong C K, Tamura Y, Yoshida A, Shielding effects on wind force correlations and quasi-static wind load combinations for low-rise building in large group, J. Journal of Wind Engineering \& Industrial Aerodynamics, 2013, 112(112):58 70.

[2] GU Ming, HUANG Qiang, HUANG Peng, et al. Numerical simulation of effects of roof factors on mean wind Pressure on gableroofed low-rise buildings with eaves, J. Journal of Building Structures.2009,30(5):205 211.

[3] Pindado S, Meseguer J, Franchini S, Influence of an upstream building on the wind-induced mean suction on the flat roof of a lowrise building, J. Journal of Wind Engineering \& Industrial Aerodynamics, 2011, 99(8):889 893

[4] Dai Y, Yan X, Ye L, Numerical simulation of interference effects of local wind pressures on roof of low-rise buildings, J. Journal of Natural Disasters, 2015, 24(1):224 233.

[5] HUANG Peng, PENG Xin-lai, GU Ming. Effects of eave shapes on wind pressure of gable-roof low-rise buildings, J. Journal of Vibration and Shock, 2012,31(5): 144 147.

[6] TAO Ling, HUANG Peng, QUAN Yong, et al. Effect of ridge and protruding gable wall on wind loadings on low-rise buildings' roof, J. Engineering Mechanics. 2012,29 (4): 113 121,127.

[7] HUANG Peng, TAO Ling, QUAN Yong, et al. Effect of eaves gutter on wind loadings on low-rise buildings' roof, J. Engineering Mechanics.2013,30(1):248 254. 
[8] Liu Shuai, Xie Zhuangning, Shi Bristol. The tent type low rise building roof wind load characteristics and wind resistant aerodynamic measures, J. Journal of building structures, 2011, (04): 9 16.
[9] Chen Ya-nan, Zhou Dai, Sun Ying-hao. Wind load characteristics and flow field analysis ofannular cantilever cantilevered roofs, J. Journal of building structures, 2012,33 (05): 53 61.

[10] Ozmen Y, Baydar E, Beeck J P A J V. Wind flow over the low-rise building models with gabled roofs having different pitch angles, J. Building \& Environment, 2015:63 74 